\title{
DENDROCHRONOLOGICAL INVESTIGATIONS IN THAILAND
}

by

\author{
Brendan M. Buckley ${ }^{1}$, Mike Barbetti ${ }^{2}$, Manas Watanasak ${ }^{3}$, \\ Rosanne D'Arrigo ${ }^{4}$, Saran Boonchirdchoo ${ }^{3}$ \& Sakunyut Sarutanon ${ }^{3}$
}

\begin{abstract}
SUMMARY
Some of the first tree-ring chronologies from mainland Southeast Asia have been developed from Thailand, and a significant link between climate and tree growth has been suggested. Four chronologies from two species of pine (Pinus kesiya Royle ex Gordon and Pinus merkusii Jungh. $\&$ de Vriese) from northeastern, lower northern and northwestern Thailand have been constructed: three from $P$. kesiya and one from $P$. merkusii. A second $P$. merkusii chronology is being developed from samples from northwestern Thailand. Preliminary climate modelling demonstrates significant relationships for tree growth with both temperature and precipitation for both species. A significant, direct relationship is revealed with temperature at the beginning of the wet season for Pinus merkusii from Thung Salaeng Luang National Park, along with an inverse relationship with precipitation for the same period. It is also suggested that the month of November (the transitional month from wet to dry season) during the year of growth is most important for Pinus kesiya from Nam Nao National Park, based on significant, direct relationships with both temperature and precipitation. The dendrochronological potential of another species, the long-lived Podocarpus neriifolius, is also discussed.
\end{abstract}

Key words: Dendrochronology, Thailand, Pinus, Southeast Asia, Podocarpus, climate.

\section{INTRODUCTION}

Dendrochronological studies in the world's lower latitudes have been few, and have met with limited success (Mariaux 1981; Worbes 1985; Jacoby 1989). Problems commonly encountered in low latitudes may derive from insufficient climatic seasonality to initiate the development of annual rings. Consequently, many tropical tree species have little or no discernible ring structure. When rings are present they are often indistinct or intra-annual, and may exhibit little common variability between trees (Jacoby 1989). Whereas seasonal radial growth of higher latitude trees may cease with the

1) Institute of Antarctic and Southern Ocean Studies, University of Tasmania, GPO Box 252C, Hobart, Tasmania 7001, Australia.

2) NWG Macintosh Centre for Quaternary Dating, University of Sydney, NSW 2006, Australia.

3) Faculty of Environment and Resource Studies, Mahidol University, Nakhon Pathom 73170, Thailand.

4) Tree-Ring Laboratory, Lamont-Doherty Earth Observatory, Palisades, N.Y. 10964, U.S.A. 
onset of a cold winter, trees from lower latitudes might continue to grow throughout the year, with most influences on growth resulting from stand dynamics, competition, human activities, or other non-climatic parameters.

The Asian monsoon produces a strong seasonality in precipitation across much of Asia, with distinct wet and dry seasons. In the case of central and northern Thailand, rainfall arrives almost entirely from the southwesterly flow associated with the summer monsoon from May to October. Orographic barriers to the north and east of Thailand, in China and Vietnam respectively, impede the northeasterly flow associated with the winter monsoon. Consequently, very little rainfall reaches the interior of Thailand between November and April.

The potential for developing climatically-sensitive tree-ring series from Southeast Asia has been demonstrated in Java where there is also pronounced seasonality in rainfall. The wet and dry seasons in Java are opposite to those of interior Thailand; the austral summer monsoon occurs from November to April, and the dry season from May to October (Berlage 1931; De Boer 1951).

Successful crossdating (the matching of ring-width patterns and/or ring characteristics between trees in order to determine the exact calendar year of each ring) in Javanese teak has enabled researchers to develop an important proxy of regional rainfall (Berlage 1931; De Boer 1951; Murphy \&Whetton 1989; Jacoby \& D'Arrigo 1990; D'Arrigo et al. 1994; Palmer \& Murphy 1993). Rainfall variability from this region has been closely linked to the behaviour of El Niño/Southern Oscillation (ENSO; Hackert \& Hastenrath 1986; Allan 1988; Cole et al. 1992). D'Arrigo et al. (1994) demonstrate a significant correlation between ring widths from Javanese teak and the Southern Oscillation Index (SOI). Teak trees from Thailand have also been shown to exhibit annual ring structure. Crossdating is possible and significant links with precipitation have been established (Pumijumnong et al. 1995a, b).

\section{MATERIAL AND METHODS}

\section{Field sampling}

Following a pilot sampling of a single, fallen Pinus merkusii tree in 1989, dendrochronological investigations in Thailand were undertaken between 1992 and 1994 from latitudes $15^{\circ} \mathrm{N}$ to $20^{\circ} \mathrm{N}$. The sampling locations and meteorological stations used are indicated on the map in Figure 1. Figure 2 shows the average monthly precipitation at the six stations. The species and number of trees sampled in each of these locations are listed in Table 1.

The main objective was to sample the two species of pine found in Thailand $(P$. kesiya and P. merkusii; known locally as three-leaf and two-leaf pine, respectively). We also tnok samples from other species which were thought to have potential for annual ring structure and crossdating, most notably four podocarp species (Podocarpus neriifolius D. Don, $P$. wallichianus Presl, $P$. imbricatus Blume, and Dacrydium elatum Wall.). A birch species (Betula alnoides Buch.-Ham.) was also sampled from Khao Yai National Park, along with test samples from various species of oaks and dipterocarps (see Table 1). 


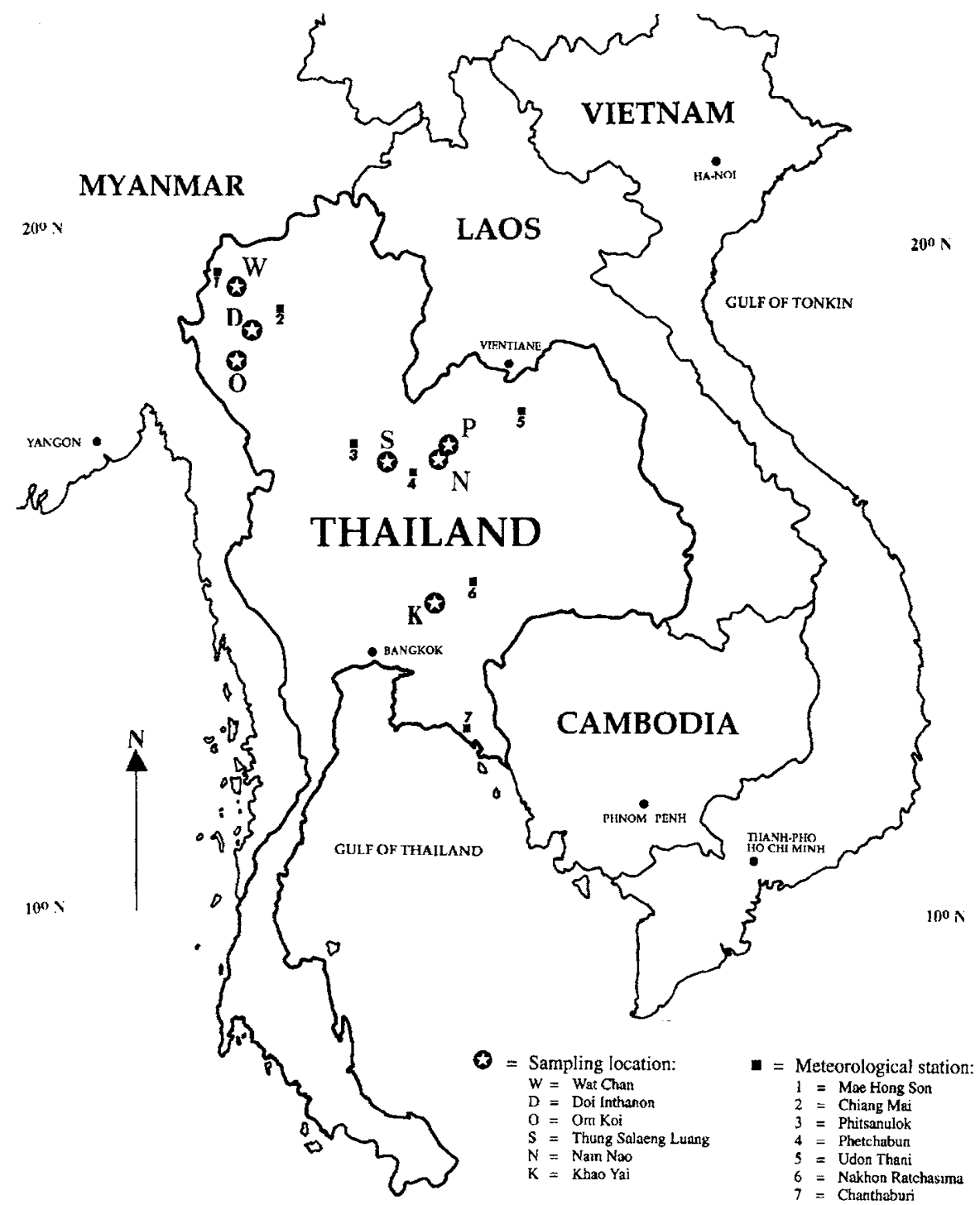

Fig. 1. Map of Southeast Asia showing locations of the tree-ring sites and the meteorological stations for this study.

Field sampling in October 1992 was concentrated in four National Parks in Thailand; Khao Yai, Nam Nao, Thung Salaeng Luang, and Doi Inthanon, with additional samples taken some $20 \mathrm{~km}$ from the town of Om Koi. In February 1993 two pine sites were sampled, at Wat Chan and Ban Sa-muang in the northwest. In June and July of 1994 we collected samples from Phu Khradung National Park and further samples from Nam Nao National Park. Core samples were taken from living trees using increment corers, and cross sections were cut from fallen trees. 
Table 1. List of species and numbers of trees sampled in each of the locations shown in Figure 1; numbers in brackets indicate fallen trees from which sections were obtained. The standard of at least 2 cores per tree was employed in most instances. $K Y=$ Khao Yai National Park; $N=$ Nam Nao NP; SL = Thung Salaeng Luang NP; DI = Doi Inthanon NP; OK = Om Koi; WJ = Wat Chan, BS = Ban Sa-muang, PK = Phu Kradung NP.

\begin{tabular}{lclllllll}
\hline Species & KY & PK & NN & SL & DI & OK & WJ & BS \\
\hline Pinus kesiya & - & $15(2)$ & $31(12)$ & - & 5 & 12 & 7 & 5 \\
Pinus merkusii & - & $14(10)$ & 4 & $20(3)$ & - & - & $12(1)$ & - \\
Podocarpus neriifolius & 11 & - & - & - & $14(3)$ & - & - & - \\
Podocarpus imbricatus & $9(1)$ & - & - & - & - & - & - & - \\
Podocarpus wallichianus & 10 & - & - & - & - & - & - & - \\
Dacrydium elatum & 12 & $7(1)$ & - & - & - & - & - & - \\
Betula alnoides & 5 & - & - & - & - & - & - & - \\
Dipterocarpus obtusifolius & - & - & $1(1)$ & - & - & 1 & - & - \\
Shorea siamensis & - & - & - & - & 1 & - & - & - \\
Calophyllum dryobalanoides & - & 1 & - & - & - & - & - & - \\
Quercus auricoma & 1 & - & - & - & - & - & - & - \\
Quercus myrsinaefolia & 1 & - & - & - & - & - & - & - \\
Quercus saravanensis & 1 & - & - & - & - & - & - & - \\
Lithocarpus rodgerianus & 1 & - & - & - & - & - & - & - \\
Choerospondias axillaris & 1 & - & - & - & - & - & - & - \\
Schima wallichii & 2 & - & - & - & - & - & - & - \\
Sapium discolor & 1 & - & - & - & - & - & - & - \\
Lophopetalum wallichii & 1 & - & - & - & - & - & - & - \\
Gironniera perrosa & 1 & - & - & - & - & - & - & - \\
Unidentified spp. & 1 & $-(1)$ & - & - & $1(5)$ & - & - & - \\
\hline
\end{tabular}

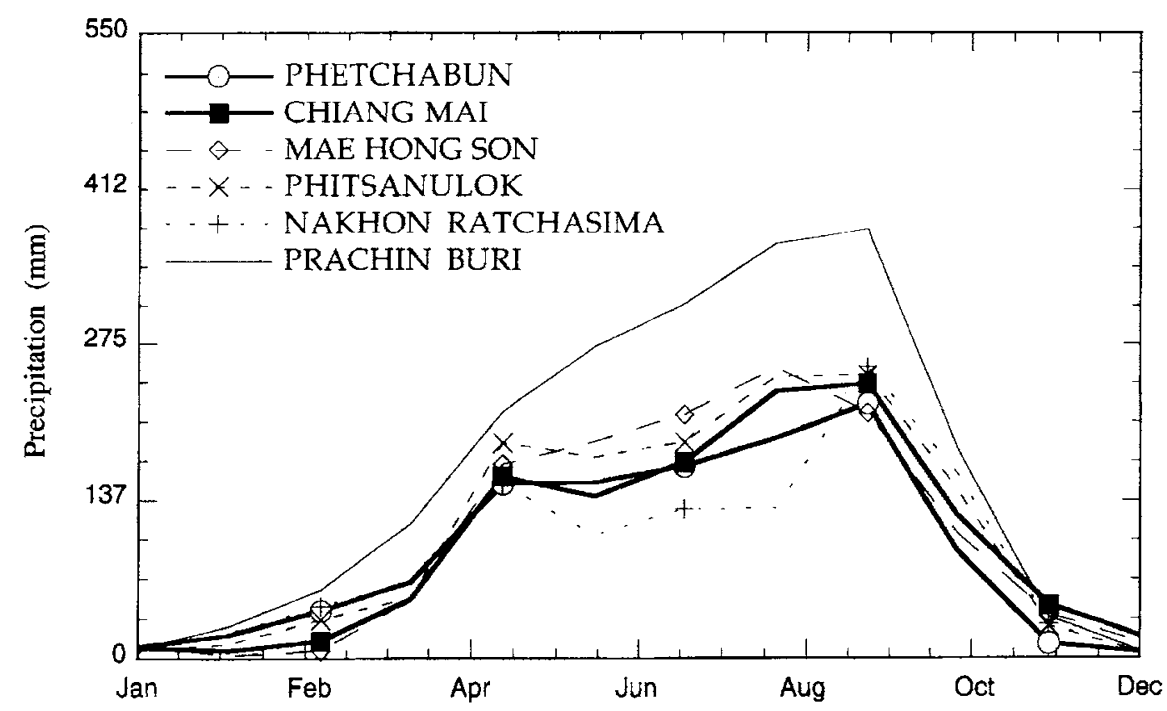

Fig. 2. The average monthly precipitation at six stations across Thailand. Locations of these sites are shown in Figure 1. The wettest months for all stations are June through September, and even across a large region there is strong agreement between the onset of the wet and dry seasons. The very high spike in rainfall (nearly $400 \mathrm{~mm}$ ) for Prachin Buri reflects its location near the coastline. Also of note is the reduction in wet season rainfall at Nakhon Ratchasima, which is situated to the northeast of Khao Yai National Park, in the rainshadow of Khao Khieo. 

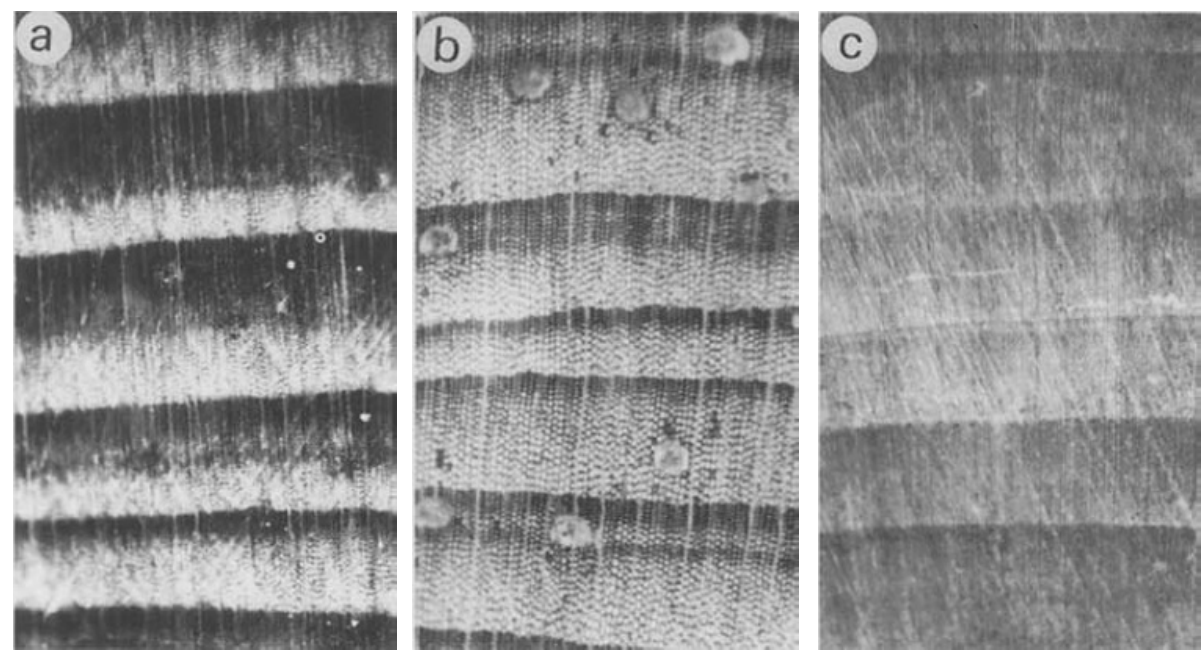

Fig. 3. Ring structure in three tree species from Thailand: (a) Pinus kesiya, $\times 15$; (b) P. merkusii, $\times 20$; (c) Dacrydium elatum, $\times 12$. The intra-annual banding in the rings of $P$. merkusii is possibly related to anthropogenic gouging and burning of living trees.

\section{Ring structure, crossdating and chronology development}

Core samples and cross sections were prepared for analysis following well-established methods for drying, mounting and surfacing (Stokes \& Smiley 1968; Swetnam et al. 1985), and the ring structure of the various species was microscopically examined.

The two pine species showed definite annual ring structure, and crossdating was readily established, particularly for $P$. kesiya. Inter-annual variability in ring widths of $P$. kesiya (Fig. 3a) was immediately evident, while intra-annual (false) ring boundaries, though occasionally present, were easily detected. Chronology development was therefore relatively straightforward for this species.

The ring structure of P. merkusii (Fig. 3b), however, was more difficult to interpret. This is partly because the highly-resinous $P$. merkusii trees are selectively gouged and $/$ or burnt by hilltribe people. At Wat Chan, for example, we sampled 13 P. merkusii stems; all of them recently gouged and some burnt as well. In Nam Nao National Park, most $P$. merkusii stems that we found had been severely injured, with multiple scars in some cases nearly girdling the trees. Therefore only four trees from that site were judged suitable for sampling. Pinus merkusii samples from both of these sites exhibited numerous false-ring boundaries and traumatized rings, possibly related to such human activities. At Thung Salaeng Luang National Park, where 23 P. merkusii were sampled, there had been occasional scarring and burning, though far less severe than at Wat Chan or Nam Nao. We were able to successfully crossdate most of the cores from this site, and thereby develop the only chronology for this species so far.

While most of the podocarps appeared to have many hundreds of rings, the ring boundaries were often indistinct, and poor circuit uniformity and wedging of rings was observed (Fig. 3c). Nevertheless, at least one of the podocarps, P. neriifolius, has shown 
Table 2. Chronology statistics from the four sites. Showing the time-span covered by the chronologies, the number of series included in each chronology, the series intercorrelations, the average mean sensitivity ( $=$ the mean percentage change from each measured yearly ring value to the next; ranging from 0.0 where there is no difference to 2.0 where a zero value occurs next to a nonzero one in the time series), and the mean autocorrelation coefficient of the unfiltered series before autoregressive modelling.

\begin{tabular}{lccccc}
\hline Site & time-span & $\begin{array}{c}\text { number } \\
\text { of series }\end{array}$ & $\begin{array}{c}\text { series } \\
\text { intercorrelations }\end{array}$ & $\begin{array}{c}\text { mean } \\
\text { sensitivity }\end{array}$ & $\begin{array}{c}\text { mean } \\
\text { autocorrelation } \\
\text { efficient }\end{array}$ \\
\hline WJK & $1852-1992$ & 16 & .577 & .282 & .681 \\
NNK & $1789-1994$ & 45 & .555 & .314 & .682 \\
SLM & $1835-1992$ & 20 & .459 & .261 & .744 \\
PKK & $1829-1993$ & 26 & .523 & .358 & .623 \\
\hline
\end{tabular}

some degree of crossdating between two trees from Doi Inthanon National Park (see Table 4). Other sampled species, listed in Table 1, have shown indistinct ring structure or poor circuit uniformity, but analyses are incomplete. Further sampling of some of these species near the limits of their distribution may enhance the possibility of finding climatically-stressed trees, with clear annual ring structure.

Standard methods were used for crossdating (Stokes \& Smiley 1968; Fritts 1976). Individual radii were dated visually, then measured to $0.001 \mathrm{~mm}$ accuracy, using a sliding-stage micrometer interfaced with a computer. The dating of measured series was then statistically confirmed with the program COFECHA which tests each series against the rest of the site by means of correlation statistics (Holmes 1983).

Following confirmation of the crossdating, the individual time-series were detrended and standardized into chronology form using the program ARSTAN (Cook 1985; Cook $\&$ Holmes 1985). We conservatively detrended each series using either a negative exponential curve or a line of horizontal or negative slope, as individual series most nearly conformed to a negative exponential growth curve. Autoregressive modelling was also employed to reduce the autocorrelated noise component in the detrended series due to endogenous disturbances or out-of-phase fluctuations. A robust mean was used to reduce the influence of outliers in the computation of the mean chronology. Two versions of the final chronology are discussed in this paper; a standard (STD) chronology which has been detrended but not pre-whitened, and a residual (RES) chronology which has been pre-whitened by autoregressive modelling.

\section{RESULTS}

The four pine chronologies developed in this study are shown in Figure 4. Three of these are from Pinus kesiya; one from Nam Nao National Park (NNK), one from Phu Kradung National Park (PKK), and one from Wat Chan (WJK). The single chronology from $P$. merkusii is from Thung Salaeng Luang National Park (SLM). A second $P$. merkusii chronology, from Wat Chan (WJM), is presently being developed. 
INDICES

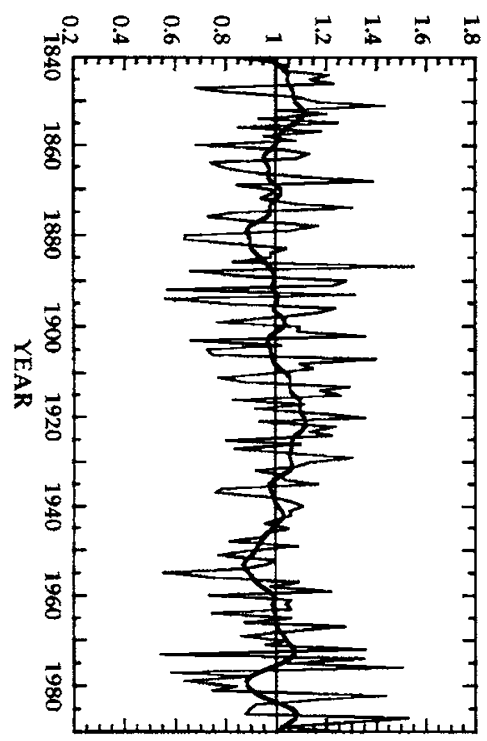

INDICES
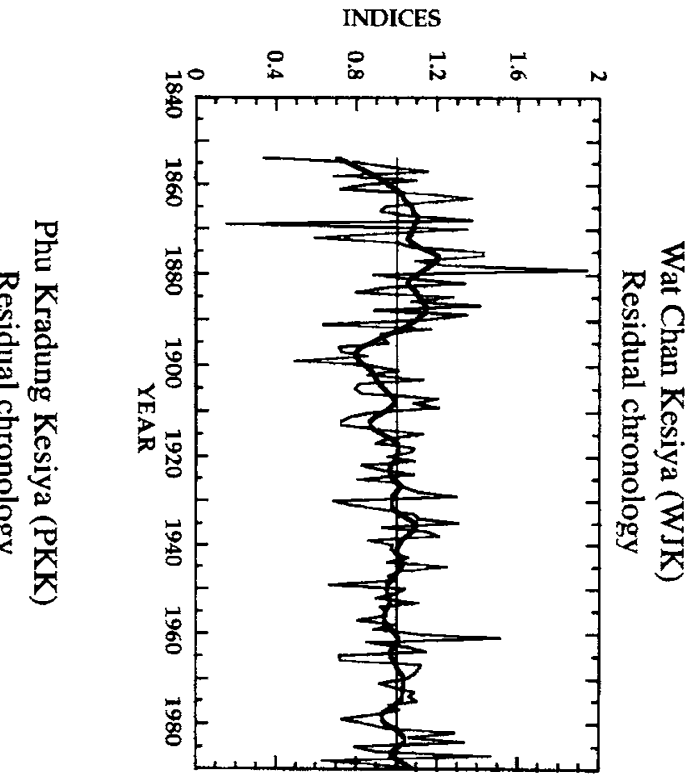
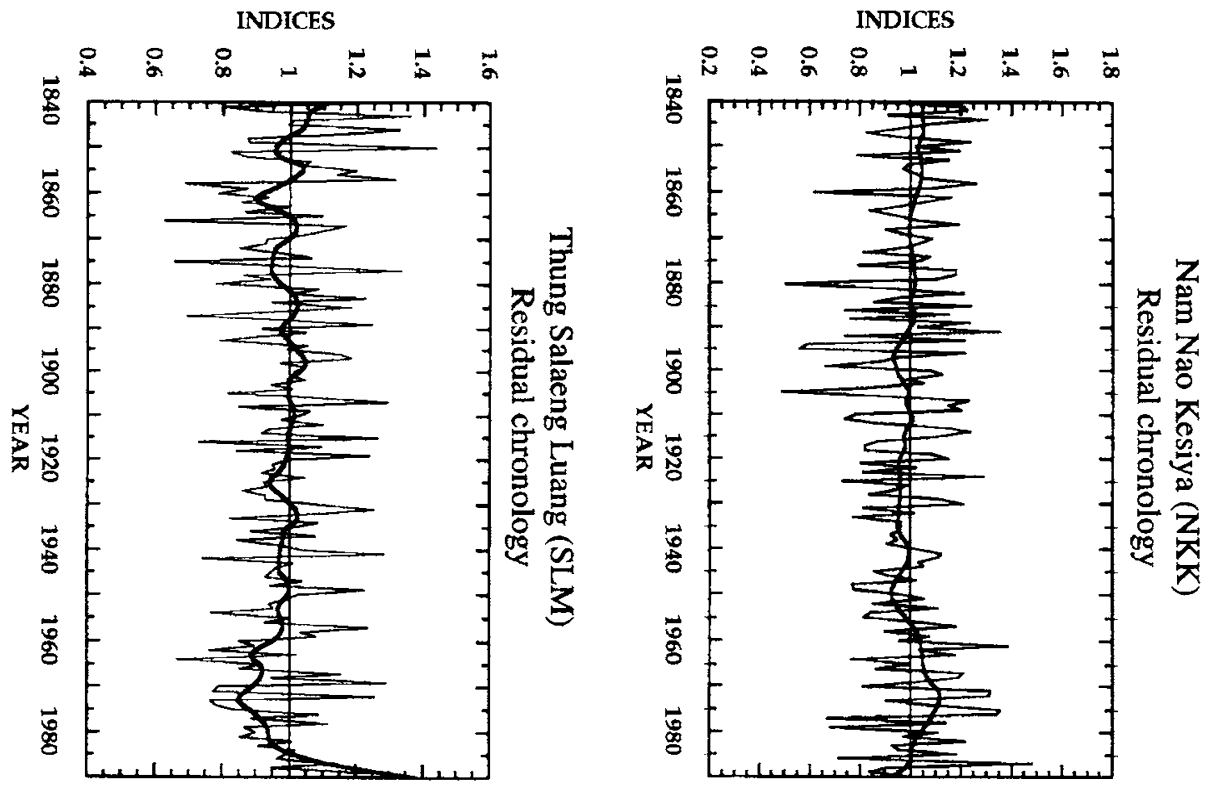

Fig. 4. Residual (prewhitened) versions of the four pine chronologies. WJK = Pinus kesiya from Wat Chan; NNK = P. kesiya from Nam Nao National Park; PKK = P. kesiya from Phu Kradung National Park; SLM = P. merkusii from Thung Salaeng Luang National Park. Series statistics are shown in Table 2. 
Table 3. Correlation matrix of all standard (S) and residual (R) chronologies.

\begin{tabular}{lrrrrrrrr}
\hline Site & WJK.S & WJK.R & SLM.S & SLM.R & NNK.S & NNK.R & PKK.S & PKK.R \\
\hline WJK.S & 1.000 & .863 & -.033 & .009 & .255 & .185 & .045 & .054 \\
WJK.R & .863 & 1.000 & .029 & .019 & .257 & .247 & .111 & .137 \\
SLM.S & -.003 & .029 & 1.000 & .938 & .080 & .175 & .174 & .171 \\
SLM.R & .009 & .019 & .938 & 1.000 & .127 & .203 & .172 & .188 \\
NNK.S & .255 & .257 & .080 & .127 & 1.000 & .867 & .490 & .475 \\
NNK.R & .185 & .247 & .175 & .203 & .867 & 1.000 & .480 & .557 \\
PKK.S & .045 & .111 & .174 & .172 & .490 & .480 & 1.000 & .917 \\
PKK.R & .054 & .137 & .171 & .188 & .475 & .557 & .917 & 1.000 \\
\hline
\end{tabular}

The pertinent statistics for the four chronologies are listed in Table 2. The highest series intercorrelations (a statistical measure of the agreement of all of the ring-width series included in a site; values above 0.328 exceed the $99 \%$ confidence limits based on the student's t-test with 50 observations) were found in the three $P$. kesiya sites (WJK = $0.577, \mathrm{NNK}=0.555$, and $\mathrm{PKK}=0.523$ ), while the lone $P$. merkusii site had a lower series intercorrelation $(\mathrm{SLM}=0.459)$.

The correlations between the four sites, for both STD and RES chronologies, are listed in Table 3. The agreement between the PKK and NNK chronologies, some 30 $\mathrm{km}$ apart, is quite strong ( $\mathrm{r}=0.557$ for the RES chronologies). The NNK site also compares reasonably well with the WJK site ( $r=0.255$ for the STD), considering that they are $450 \mathrm{~km}$ apart. Though the SLM site is only $60 \mathrm{~km}$ away from NNK, and of similar elevation (around 900 metres), the correlation between the two sites is quite low ( $r=0.203$ for the RES). The agreement between SLM and PKK is also weak $(\mathrm{r}=0.188$ for the RES). This may be due to interspecies differences in growth characteristics, microsite requirements, or response to climate. This question needs to be addressed in future studies. The SLM site exhibits essentially no agreement with the WJK site ( $r=0.019$ for the RES).

It is encouraging that $P$. kesiya sites many kilometres apart can be crossdated. As noted above, it is likely that the lower correlation between the two pine species simply reflects inter-species differences. It is also plausible, however, that the growth of P. merkusii at the SLM site has been affected by human activities as noted earlier. While we did not see extensive gouging of trees at Thung Salaeng Luang National Park, there was evidence of repeated burning, possibly anthropogenic in origin. It is unclear at this stage whether the greater frequency of false-ring boundaries found in P. merkusii (see Fig. 3b) is related to burning or is climatic in origin. A more thorough analysis should be aided by the inclusion of several cross sections taken in 1993 and 1994, as well as the analysis of additional sites with minimal human impact.

In addition to the pine species, crossdating has been demonstrated for one of the podocarp species we sampled, Podocarpus neriifolius. Cross sections were obtained from three trees of this species, at Doi Inthanon National Park in February of 1993. 
Table 4. Statistics for three radii from two cross sections of Podocarpus neriifolius from Doi Inthanon National Park. Intervals are arbitrary years as the sections are from logs found on the forest floor, the outer date is not known. The correlation of each full series with the others and the agreement between 50 -year segments of each series, lagged by 25 years is given. Low correlations in the early segments reflect growth characteristics of juvenile, sub-canopy rain forest trees.

\begin{tabular}{ccccccc}
\hline & & & 1000 & 1025 & 1050 & 1075 \\
Series & Interval & Correlation & 1049 & 1074 & 1099 & 1174 \\
DIN 155A & $1001-1132$ & .370 & .25 & .44 & .42 & .45 \\
DIN 155B & $1001-1121$ & .316 & .18 & .51 & .47 & .31 \\
DIN 156A & $1005-1113$ & .343 & .15 & .47 & .51 & .41 \\
\hline
\end{tabular}

They were surfaced, and two radii from each section were measured. Statisticallysignificant crossdating was discovered between two of the trees, as shown in Table 4. Twenty-five trees of this species were cored at Khao Yai and Doi Inthanon National Parks, and some of them have many hundreds of growth rings. These core samples appeared difficult to work with and were initially put aside, but the crossdating from these cross sections illustrates the potential of this species, which may prove to be important for dendrochronological studies on a longer time-scale than is afforded by the pines.

\section{Climate response modelling}

The season of growth for trees at these sites is likely to be in the rainy months between May and October. Presumably, annual growth would begin with the onset of the monsoonal rains, though this has not actually been determined through direct field observation. The dry season, between November and April, is likely a period of relative dormancy for the trees, and the timing of the onset of both the dry and wet seasons should have an influence on annual growth. It would seem logical that growth might be enhanced by increased available moisture over a longer period of the year, particularly during the normally-dry months.

Preliminary climate modelling was performed for each of the chronologies, using nearby meteorological stations from throughout the region. Figures 5 through 8 highlight the climate response for the NNK and SLM sites with Phitsanulok and Phetchabun rainfall and temperature parameters. Both of these stations are within $140 \mathrm{~km}$ of the tree sites (see Fig. 1), though at lower elevations. The time-span of all available climate data sets for both Phitsanulok and Phetchabun is from 1951 to 1991. This period of 40 years, while rather short for statistical comparison, was all that was available for use in this study.

We analysed the correlation functions (the series of correlation coefficients between a ring-width chronology and each of several sequential climatic variables) for the pre-whitened RES chronologies with the following climatic parameters; total monthly rainfall, the number of rain days per month, mean temperature, and mean minimum temperature. The correlation function was used as a preliminary interpretative guide, 

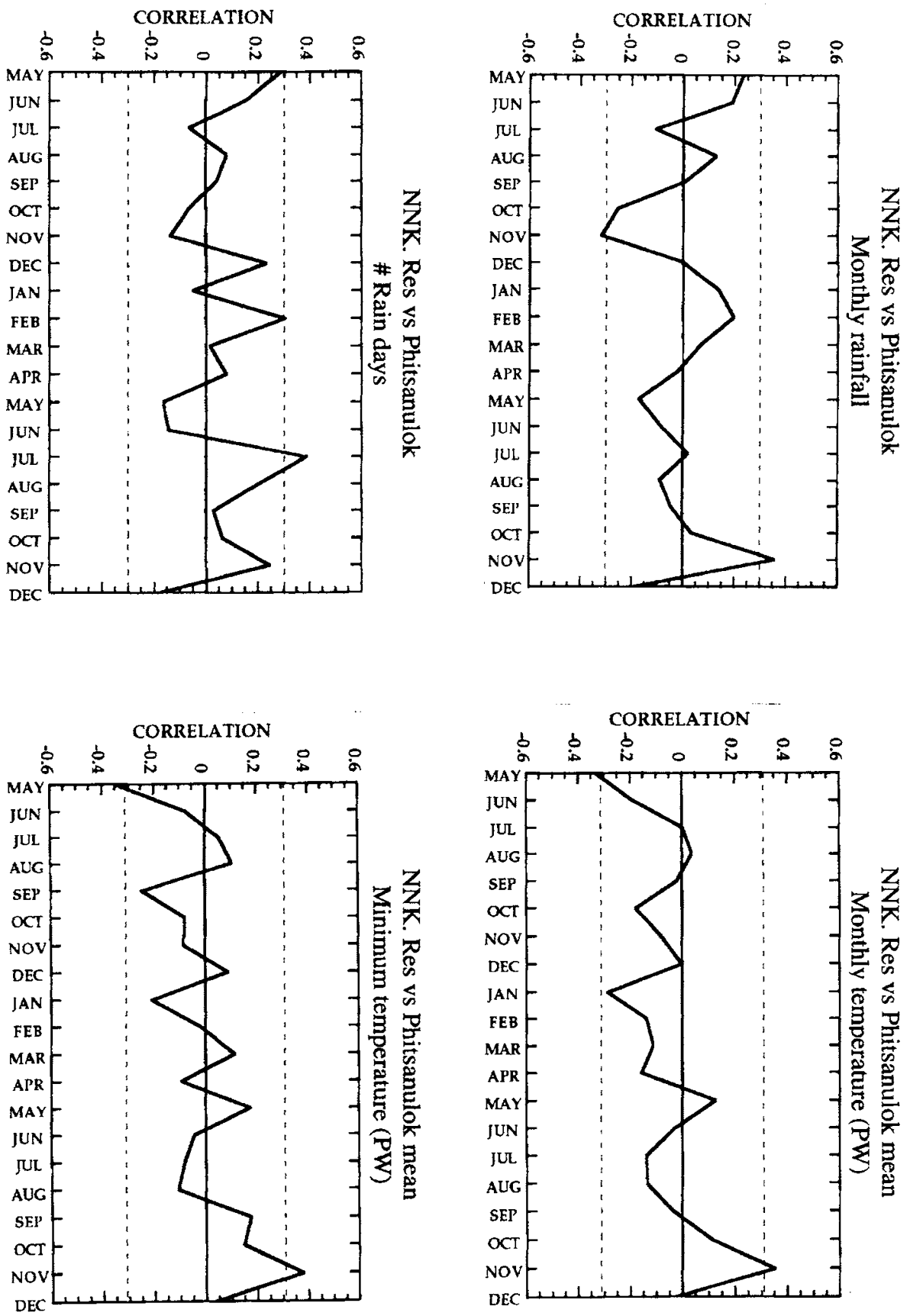

Fig. 5. Climate response plots for the NNK site with Phitsanulok meteorological data. The correlation between the residual chronology and different meteorological parameters is given for the 20-month period from May of the previous year to the December of the year based on the records from 1951 to 1991. The period covers one dry season (Nov.-Apr.) bracketed by two wet seasons. Dashed lines indicate the $95 \%$ confidence limits. 

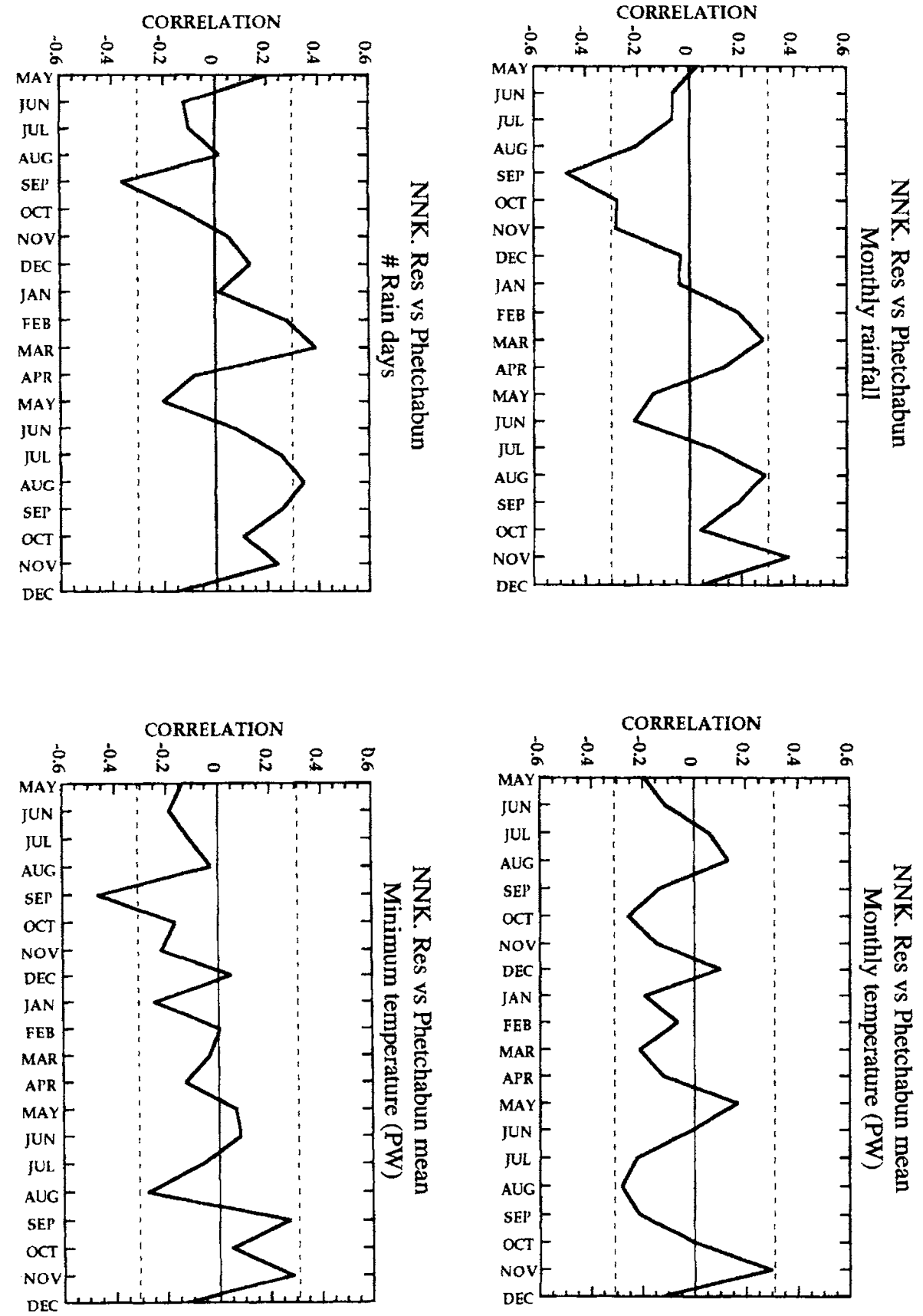

Fig. 6. Climate response plots for the NNK site with Phetchabun meteorological data. 

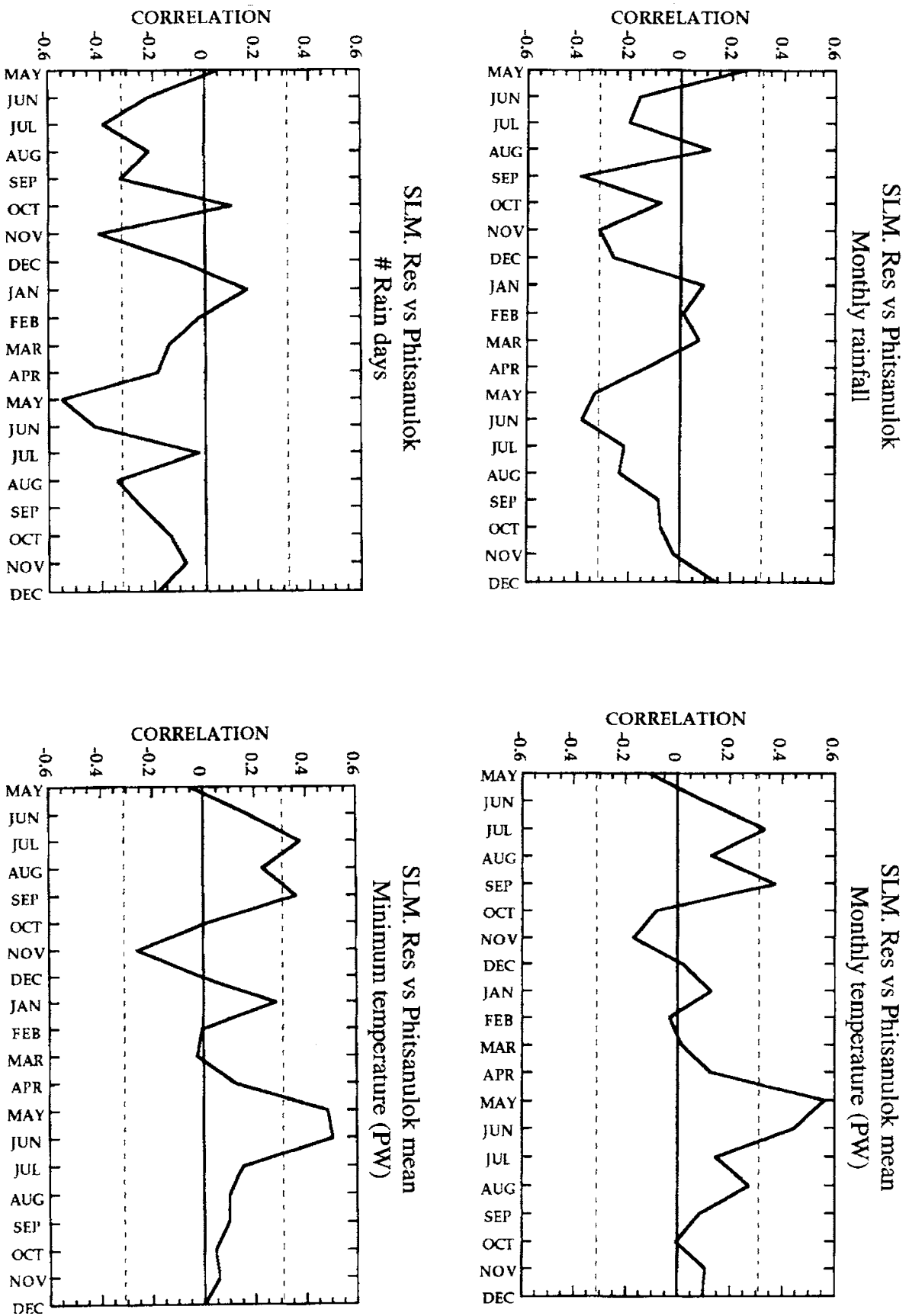

Fig. 7. Climate response plots for the SLM site with Phitsanulok meteorological data. 

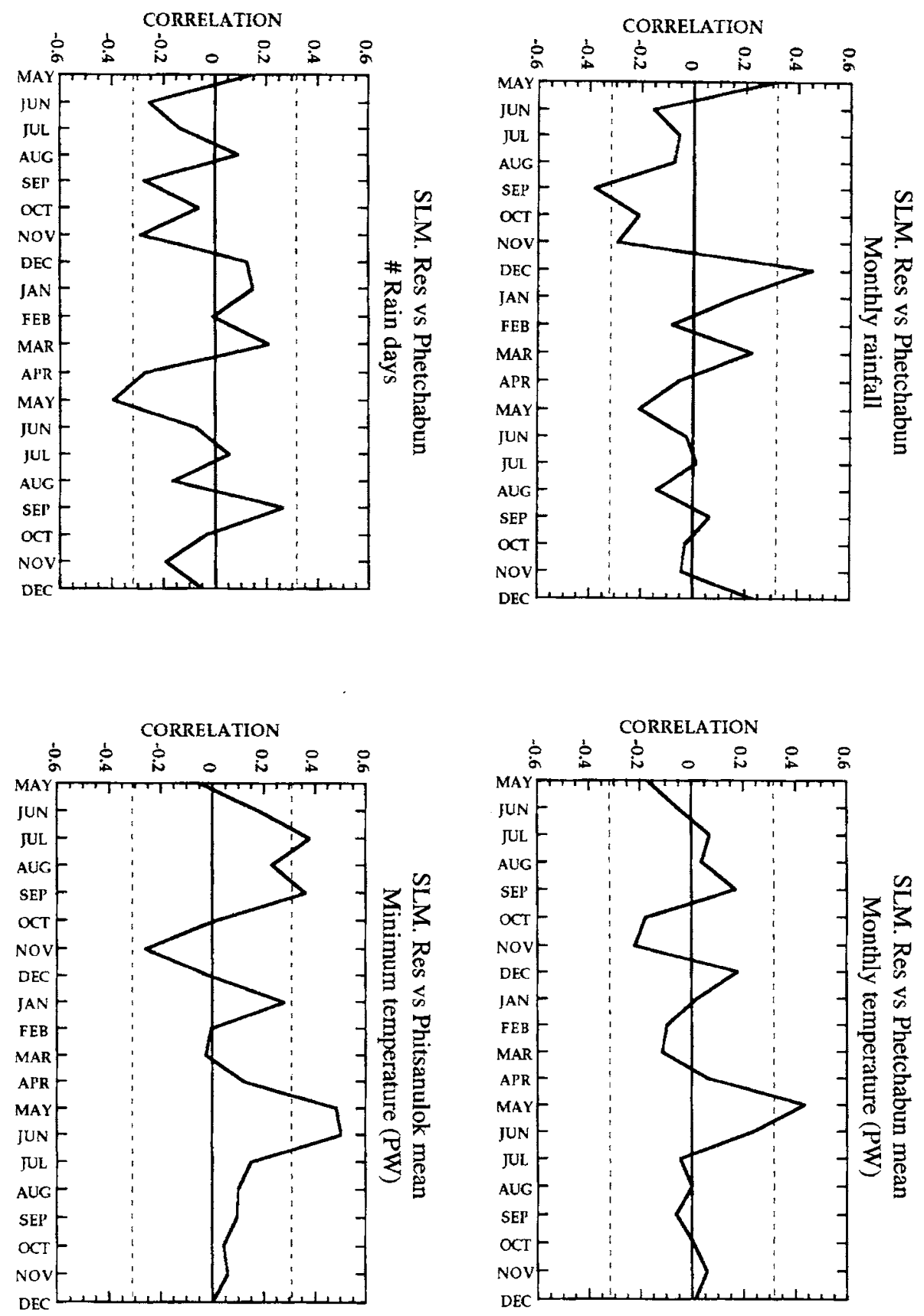

Fig. 8. Climate response plots for the SLM site with Phetchabun meteorological data. 
as suggested by Blasing et al. (1984), in order to avoid the subjective decisions associated with introducing orthogonalized climatic variables into regression, as is done with traditional response-functions analyses.

A twenty-month dendroclimatic year was used for comparison, extending from December of the year of growth back to May of the year prior. The temperature data were first pre-whitened to remove the effects of autocorrelation. While it is recognized that the precipitation data are non-parametric (the dry season months routinely experience no rainfall, while the wet season months have a highly-variable maximum value) no attempt was made in this preliminary investigation to accommodate this.

The NNK site shows a direct relationship with total monthly precipitation for November of the growing season at both stations, significant at the 0.05 level (Fig. 5 \& 6). This suggests that the transition from the wet to dry season is important to growth; increased rainfall in November indicates an extended monsoon, and therefore a longer window of growth. There is also a significant, direct relationship with the number of rain days in August of the growing season at both stations, and with March of the present year at Phetchabun, again indicating the importance of a prolonged monsoon.

Significant, inverse relationships are suggested for the year prior to growth (September for both rainfall parameters at Phetchabun, and the November monthly rainfall at Phitsanulok). It is possible that such a relationship may simply be a statistical artifact due to comparison with a relatively short climate data set, yet this may also underlie a true physiological requirement for drier conditions at the end of the previous wet season (i.e., an early departure of the monsoon) for maximum growth potential in a given year. A mechanism to explain this putative relationship would be beyond the scope of this paper, but it may be clarified by more detailed physiological response monitoring which is planned for the near future in at least one of the study sites. Additionally, comparison with more lengthy climate records would allow for greater degrees of freedom and a more robust estimate of the growth response.

The temperature response of the NNK site shows a significant, direct relationship with November mean, and mean minimum, temperature at Phitsanulok. The higher mean minimum temperature is consistent with the direct response to precipitation for the same month. Since precipitation and cloudiness are intercorrelated, drier conditions would result in increased radiative cooling at night, thereby lowering the minimum temperature. Again, the significant inverse relationship for September of the previous year can be seen for Phetchabun mean minimum temperature. This is consistent with the response to precipitation for the same month, with lower minimum temperatures suggesting less cloudy conditions and reduced rainfall.

The response of the SLM site is largely negative with precipitation through much of the year, and largely positive with temperature. Significant relationships are again revealed for September of the prior year at both stations (negative for monthly rainfall at both stations, and positive for both temperature parameters at Phitsanulok). This is similar to the findings for NNK. Perhaps more interesting, however, is the rather strong, negative response for the number of rain days in May of the growing season (Fig. 7), which is mirrored by the very strong, direct relationship with temperature for the same month at both stations (Fig. $7 \& 8$ ). This would suggest that warmer and drier condi- 
tions during the beginning of the wet season are favourable to growth for $P$. merkusii trees at Thung Salaeng Luang.

The work presented here demonstrates the potential for paleoclimatic research using tree rings from at least two species in this region; however, caution is necessary in interpreting these results. It is important to reiterate the need for longer meteorological records for comparison with the tree-ring series developed in this study. Further, it is clear that more detailed climate-response monitoring is required at the study locations. Site characteristics such as elevation, slope, aspect, soil depth and type, may be very important features in determining growth at a given site.

\section{DISCUSSION}

We have demonstrated the dendrochronological potential of three tree species from Thailand; Pinus kesiya, P. merkusii, and Podocarpus neriifolius. The most promising of these species, $P$. kesiya, has been used to construct three chronologies which crossdate both temporally and spatially. A significant response with temperature and precipitation has been demonstrated for both pine species, perhaps a bit stronger for $P$. merkusii. The potential of $P$. kesiya for use in regional applications is illustrated by the crossdating between the WJK and NNK sites, $450 \mathrm{~km}$ apart, and the very strong crossdating between the NNK and PKK sites, $30 \mathrm{~km}$ apart. The usefulness of $P$. merkusii for this purpose is presently less clear. Significant crossdating has been demonstrated for the SLM site, though the agreement with a $P$. kesiya chronology about $60 \mathrm{~km}$ away is weak. While this may reflect interspecies differences, it could be related to anthropogenic, or other non-climatic factors.

Significant crossdating between radii from two cross sections of the long-lived Podocarpus neriifolius has also been demonstrated. Cores from twenty-five trees of this species have been sampled, and will be reanalysed for crossdating potential. Initial analyses of all of the podocarp species did not appear promising, but since they offer the greatest potential for long-chronology development they will undergo further study. Their usefulness in paleoclimatic reconstruction, however, is still uncertain.

\section{Future Research}

Many samples already collected have yet to be analysed, and with cross sections of P. merkusii from Phu Kradung National Park and Wat Chan it is likely that two more chronologies of that species will be constructed. A network of climatically-sensitive chronologies from Thailand and neighbouring countries is highly desirable. Both pine species used here are also found in Laos and southern China, and sampling efforts in those countries are being initiated. Sources of archaeological wood may be utilized in order to increase the time-span of the tree-ring series. Log caskets from northwestern Thailand have been dated using accelerator mass spectrometry (AMS), with ages ranging from 1,350 to 2,220 years before present (Hotchkis et al. 1994). While links between tree growth and climate for the species outlined in this research are tenuously established, this study marks the first step towards the goal of reconstruction of the regional climate in Southeast Asia. Future sampling will concentrate, where possible, 
on areas less subject to human impact, and new species will be analysed. While the climate modelling presented here is encouraging, longer meteorological records must be obtained for comparison. More detailed monitoring of the physiological response of both pine species to environmental factors, using dendrometer bands in conjunction with automated weather stations is planned for the near future.

\section{ACKNOWLEDGEMENTS}

This project has been made possible through the support and encouragement of Dr. Tiwa Sapakit, Director-General of the Thai Royal Forestry Department; Khun Payung Nopsuwan, Director of the National Parks Division, Thailand; Professor Debhanom Muangman, Dean of the Faculty of Environment and Resource Studies, Mahidol University; and the National Research Council of Thailand, in Bangkok.

We gratefully acknowledge the cheerful cooperation and guidance we received in all five National Parks and at Wat Chan, as well as generous assistance with accommodation. Special thanks are due to the heads, namely Wallop Sudont, Khao Yai NP; Panyaa Bunsomboon and Viroj Nuknaen, Nam Nao NP; Phairat Tharnchai, Thung Salaeng Luang NP; Puchong Insomphun, Doi Inthanon NP; Santisuk Prasittisak, Forest Industry Organisation, Wat Chan; and Phanom Phongsuwan, Phu Kradung NP.

Special thanks to Drs. E.R. Cook and G.C. Jacoby, Lamont-Doherty Earth Observatory, for assistance with the methodology and the manuscript; to Bruce Thomson, University of Sydney, and Yantao Shi, Lamont-Doherty Earth Observatory, for assistance with laboratory preparation and analyses of tree-ring samples; and to Peter Grave, University of Sydney, for fieldwork assistance. We also thank Mr. Dirakrit Bohuwech, Forecast Division, Meteorology Department, and Mrs Pintip Thitirojanawat, Office of Technical Forestry, Royal Forest Department, for providing the meteorological data.

Funding for this project came from the University of Sydney in Australia, Columbia University in the USA, and Mahidol University in Thailand. Qantas Airways assisted with transport of equipment and samples.

\section{REFERENCES}

Allan, R. J. 1988. El Niño-Southern Oscillation influences in the Australasian region. Progress in Physical Oceanography 12: 4-40.

Berlage, H.P. 1931. On the relationship between thickness of tree-rings of Djati (teak) trees and rainfall on Java. Tectona 24: 939-953.

Blasing, T.J., A.M. Solomon \& D.N. Duvick. 1984. Response functions revisited. Tree-Ring Bull. 44: 1-16.

Cole, J.E., G.T. Shen, R.G. Fairbanks \& M. Moore. 1992. Coral monitors of El Niño/Southern Oscillation dynamics across the equatorial Pacific. Chapter 18: 349-375. In: H.F. Diaz \& V. Markgraf (eds.), El Niño, historical and paleoclimatic aspects of the Southern Oscillation. Cambridge Univ. Press, Cambridge.

Cook, E. R. 1985. A time series analysis approach to tree-ring standardization. Diss. University of Arizona, Tucson.

Cook, E.R. \& R.L. Holmes. 1985. Program ARSTAN and user's manual. Tucson, Laboratory of Tree-Ring Research, University of Arizona.

D’Arrigo, D.R., G.C. Jacoby \& P. J. Krusic. 1994. Progress in dendroclimatic studies in Indonesia. Terrestrial, Atmospheric and Oceanic Sciences 5: 349-363.

De Boer, H.J. 1951. Tree-ring measurements and weather fluctuations in Java from AD 1514. Proc. Kon. Ned. Akad. Wetensch. B 54: 194-209.

Fritts, H. 1976. Tree rings and climate. London Acad. Press Inc. 
Hackert, E.C. \& S. Hastenrath 1986. Mechanisms of Java rainfall anomalies. Mon. Weath. Rev. 114: 745-757.

Holmes, R.L. 1983. Computer-assisted quality control in tree-ring dating and measurement. Tree-Ring Bull. 43: 69-78.

Hotchkis, M.A.C., D. Fink, G.E. Jacobsen, E. M. Lawson, M. Shying, A.M. Smith, C. Tuniz, M. Barbetti, P. Grave, M.Q. Hua \& J. Head. 1994. ${ }^{14} \mathrm{C}$ analyses at the Antares AMS Centre: Dating the $\log$ coffins of northwest Thailand. In: L.K. Fifield, D. Fink, S. H. Sie \& C. Tuniz (eds.): Proc. Sixth International Conf. on Accelerator Mass Spectrometry. Nuclear Instruments and Methods in Physics Research B92: 27-30.

Jacoby, G.C. 1989. Overview of tree-ring analysis in tropical regions. In: P. Baas \& R.E. Vetter (eds.), Growth rings in tropical woods. IAWA Bull. n.s. 10: 99-108.

Jacoby, G.C. \& R.D. D'Arrigo. 1990. Teak (Tectona grandis L. f.), a tropical species of largescale dendroclimatic potential. Dendrochronologia 8: 83-98.

Mariaux, A. 1981. Past efforts in measuring age and annual growth in tropical trees. In: F.H. Bormann \& G. Berlyn (eds.), Age and growth rate of tropical trees: New directions for research: 20-30. Yale Univ., School of Forestry and Environm. Studies, Bull. 94.

Murphy, J.O. \& P.H. Whetton. 1989. A re-analysis of a tree-ring chronology from Java. Proc. Kon. Ned. Akad. Wetensch. B92: 241-257.

Palmer, J.G. \& J.O. Murphy. 1993. An extended tree ring chronology (teak) from Java. Proc. Kon. Ned. Akad. Wetensch. B96: 27-41.

Pumijumnong, N., D. Eckstein \& U. Sass. 1995a. Tree-ring research onTectona grandis in northern Thailand. IAWA J. 16: 385-392 (this issue).

Pumijumnong, N., D. Eckstein \& U. Sass. 1995b. A network of Tectona grandis chronologies in northern Thailand. International Workshop on Asian and Pacific Dendrochronology, 4-9 March 1995, Tsukuba, Japan In press.

Stokes, M. \& T. Smiley. 1968. An introduction to tree-ring dating. Univ. of Chicago Press, Chicago.

Swetnam, T.W., M. Thompson \& E. Sutherland. 1985. Using dendrochronology to measure radial growth of defoliated trees. Agricultural Handbook 639, U.S. Dept. of Agriculture, Forest Service, Washington D.C.

Worbes, M. 1985. Structural and other adaptations to long-term flooding by trees in Central Amazonia. Amazonia 9: 459-484. 